\title{
Utilising a scholarship program as a workforce strategy for the community- managed mental health sector
}

\author{
Emma Foreman, Sara McMillan and Amanda Wheeler
}

\begin{abstract}
Emma Foreman is a Principal Project Officer at the Park Centre for Mental Health, West Moreton Hospital and Health Service, Wacol, Australia. Sara McMillan is based at the School of Human Services and Social Work, Griffith University, Meadowbrook, Australia. Amanda Wheeler is a Professor of Mental Health at the School of Human Services and Social Work, Griffith University, Meadowbrook, Australia.
\end{abstract}

\begin{abstract}
Purpose - The community-managed mental health sector needs to meet growing workforce demands. Yet, limited research has explored professional development opportunities and effective recruitment and retention strategies to support sector growth. One strategy is the use of a scholarship program to increase skills and training, via a University qualification. The purpose of this paper is to explore the progress of 19 mental health scholarship students and the impact of the scholarship on career intentions.

Design/methodology/approach - A mixed-methods approach comprising scholarship applications, questionnaires and semi-structured interviews was used to explore the students' university experiences between February 2013 and January 2015. Course convenors of the Mental Health Program were interviewed. Data were collected across three time-points over 24 months, with each collection informing the next research phase. Data analysis involved thematic analysis and descriptive statistics.

Findings - Deeper knowledge, recognition of experience, new career pathways and improved work practice were benefits. Managing time and study, and work-life balance were the greatest challenges. Completing students displayed a range of internal attributes and accessed external supports. At the time of the study, the scholarships maintained student motivation and intention to work in the sector.

Originality/value - This research provides a deeper understanding of the demographics of the sector's workforce. Insight into the attributes of completing students was obtained. The benefits realized and the challenges faced by the scholarship recipients will inform ongoing workforce development programs for the community-managed mental health sector.
\end{abstract}

Keywords Higher education, Workforce, Community mental health, Career intentions, Scholarships

Paper type Research paper

\section{Introduction}

With mental health needs increasing globally, non-government service providers are in high demand to deliver community-managed mental health support services (Cuthbert and Basset, 2007; Carbone et al., 2011; Mental Health Workforce Advisory Committee (MHWAC), 2011b; National Health Workforce Planning and Research Collaboration (NHWP\&RC), 2011; Canadian Mental Health Association, 2012; World Health Organisation, 2013). Consumers experiencing mental illness are supported by these not-for-profit providers to develop their independence, social wellbeing, and physical and mental health in the community (Andrews, 2005; James et al., 2006; Community Mental Health Australia, 2012). Services range from clinical treatment, to advocacy and personalized support, and include the provision of training, recreational activities, self-help support groups, accommodation and vocational assistance (Department of Health and Ageing, 2013). There are believed to be over 800 such services in Australia (Bateman and Smith, 2011) with at least 200 services operating in the state of Queensland (Health and Community Services Workforce Council, 2012).

Internationally, there are significant workforce challenges faced by the community-managed mental health sector, including low remuneration, high staff turnover, poorly defined career 
pathways and inadequate access to continuing education and training (Andrews, 2005; Aarons and Sawitzky, 2006; James et al., 2006; Cuthbert and Basset, 2007; Harkness et al., 2007; Mendoza and Wands, 2009b; Carbone et al., 2011; Maxwell-Crawford, 2011). The Australian community-managed mental health sector is largely reliant on State and Federal government funding (Doessel et al., 2011). Service contracts offered under government-led initiatives do not tend to support long-term funding security, creating constraints on staff tenure and job continuity concerns (Akingbola, 2004). Changes in funding priorities can affect the employment options offered by these organizations, resulting in a preference for part-time and casual workers to minimize organizational costs and maximize workplace flexibility to meet consumers' needs (Akingbola, 2004). However, such conditions can become less attractive over time, leading to employees leaving in search of more predictable work and pay arrangements (Akingbola, 2004; Brough et al., 2008). Furthermore, the current award rates for community-managed mental health service employees are lower than those offered for similar work performed in the public sector (Community Services and Health Industry Skills Council, 2015). This can result in staff gaining experience in the sector and then moving to better paying jobs (Gallon et al., 2003). In an Australian Council of Social Services' (2013) survey, service providers advised that they were struggling to meet consumer requirements within existing resources and, consequently, limited their service availability or worked longer hours to avoid turning consumers away.

In 2011, a detailed study was undertaken to further understand the Australian community-managed mental health workforce (NHWP\&RC, 2011). Insight into 316 organizations was obtained; employees had varied educational qualifications and professional backgrounds including psychology, social work, nursing, occupational therapy, mental health, peer work or community service delivery and tended to be represented by those seeking a career change, often later in life (NHWP\&RC, 2011). Staff turnover was reasonably low with 70 percent of respondents reporting an annual rate of 5 percent or less. This conflicted with a 2009 training and workforce profile of Queensland organizations (Mendoza and Wands, 2009b); 30 percent of respondents were considering leaving the sector in the next 12 months (Mendoza and Wands, 2009b). The staff most likely to consider leaving were those with specialist roles, e.g. counselors, social workers, and psychologists, or full-time staff earning under $\$ 30,000$ Australian dollars per annum (Mendoza and Wands, 2009b). This suggests that staff move to positions which further utilize their professional skills or offer higher remuneration. Similarly, a 2007 New Zealand study found that the average length of employment in the sector was 3.7 years, with 25 percent of the workforce having less than 12 months' experience (Platform, 2007).

Although workforce shortages are a long-term problem for this sector (MHWAC, 2011a), employees have reported being attracted to this field, based on the personal value that they place on their work, and their belief that they can make a positive difference to mental health consumers (Mendoza and Wands, 2009b). Employees may seek formal mental health qualifications to support their current skills and experience, or to support a career transition in the sector (Gethin and Deakin, 2006). Higher education opportunities have become an emerging sector priority (Queensland Government, 2011b), with stronger links encouraged between vocational education training and higher education providers to facilitate career development (Community Services and Health Industry Skills Council, 2012). Careful planning is required to ensure that the community-managed mental health workforce is suitably trained, experienced and can meet increasing service demand (Mendoza and Wands, 2009a; Queensland Government, 2011a, b; Health and Community Services Workforce Council, 2012; Queensland Mental Health Commission, 2014).

To contribute to workforce development, the Queensland Government funded 19 scholarships for community-managed sector employees. In 2012, a Queensland University was contracted to coordinate a scholarship program for students wishing to complete the online Graduate Certificate or Master of Mental Health Practice qualification (Stewart et al., 2012). This program was selected for the scholarships as it specifically catered to people working in the community-managed sector. The program supports a diverse range of applicants looking to further their mental health knowledge and capacity to deliver community and recovery-based services, but also encourages a multi-disciplinary and professional framework that complements consumers' clinical treatment (Griffith University, 2012). 
Entry to the Graduate Certificate is via completion of an undergraduate degree, or the successful completion of a relevant Certificate IV vocational education and training qualification, plus three years' experience in the mental health sector and a demonstrated ability to undertake graduate study (Griffith University, 2014). Entry to the Master of Mental Health Practice is also via the completion of an undergraduate degree with a minimum grade point average (GPA) of 5.0 and a demonstrated ability to undertake graduate study, or completion of the Graduate Certificate in Mental Health Practice with a minimum GPA of 5.0 (Griffith University, 2014).

The Graduate Certificate and Master is delivered in an off-campus, online format which allows for full-time, part-time and remote access to the program (Stewart et al., 2012). The Graduate Certificate comprises of four courses which can be completed in one to two years (40 credit points). At the time of the research commencement, the Master program comprised of six mandatory courses and two electives, and could be completed within two years of full-time study (80 credit points). In 2014, a revised program was implemented which saw the introduction of a Graduate Diploma as a third qualification option and resulted in the extension of the Masters qualification by an additional six months study to complete a research dissertation (120 credit points).

Scholarship recipients received funding for 50 percent of the program costs, half on entry to the program and half upon completion. By supporting the enhancement of mental health skills and knowledge in the industry, the scholarships had a threefold purpose: maintaining the commitment and desire of people to work in the sector; attracting skilled individuals for the growth of the sector; and supporting quality service provision to mental health consumers.

An evaluation of the scholarship program was completed to determine its efficacy as a workforce strategy. Overall, there is limited research into the features of the community-managed mental health workforce, particularly in relation to career pathways and professional development opportunities to support sector growth (Cuthbert and Basset, 2007; Health Workforce Australia, 2011). The aim of this study was to examine the use of scholarships as a strategy to maintain workers in the sector. The study explored: the benefits and challenges scholarship recipients faced; and the potential relationship between scholarships and individuals' motivation to stay in the sector.

\section{Methods}

\section{Study design}

This study was exploratory in nature as little was known about the use of university level scholarships as a workforce incentive from the literature. Research was undertaken into evaluation methods, which was found to support continuous exploration of the scholarship recipients' study journey at various time-points, an evolving study design based on emerging data, and provision for multiple sources of data (Greene et al., 1989; Baran and Jones, 2016). It was noted that evaluative studies include quantitative and qualitative data from multiple sources of information in order to triangulate the information collected, develop a level of confidence in the research findings, and minimize the likelihood of limited or biased results (Greene et al., 1989; Davidson, 2005; Baran and Jones, 2016).

The researchers chose a mixed-methods study based on Creswell and Plano Clark's "typologybased" structure involving a "convergent parallel" design (Creswell and Plano Clark, 2011). Qualitative and quantitative data collection (quan-QUAL) occurred almost simultaneously (Creswell and Plano Clark, 2011). The intertwining of qualitative and quantitative data collected at each research phase along the students' journey, informed the development of the next phase and enabled deeper understanding of key concepts articulated by participants (Figure 1). Given the limited quantitative data obtained from study participants, this paper focuses on the qualitative findings.

\section{Setting}

Scholarships were available for two online qualification programs at a South-East Queensland University, Australia in 2013 and 2014: the Graduate Certificate in Mental Health Practice 


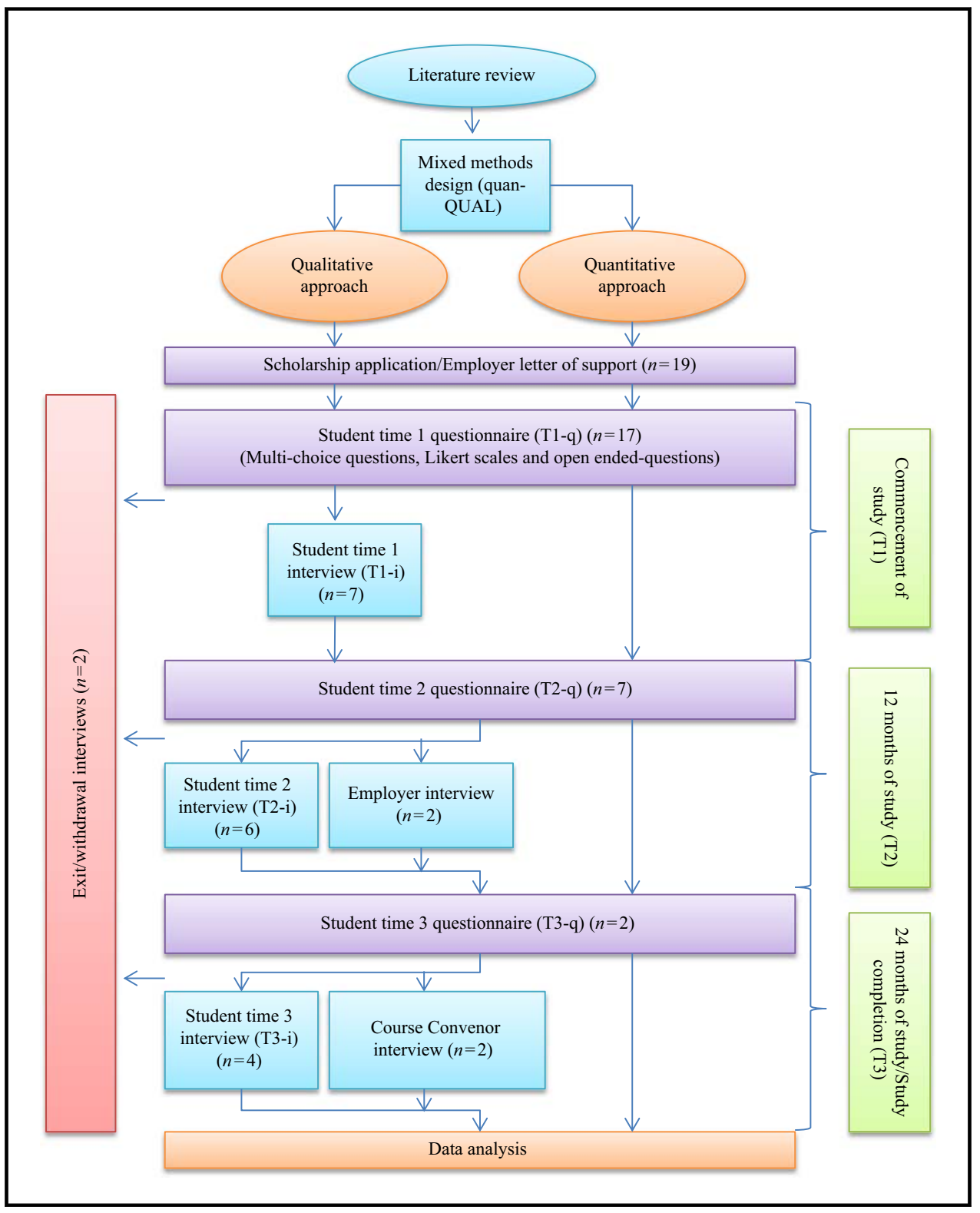

(consisting of four courses) and the Master of Mental Health Practice (consisting of eight courses) (Stewart et al., 2012). Two scholarship application rounds were undertaken in the preceding year, i.e. 2012 and 2013. Eligibility criteria further to University requirements included Queensland residence, submission of a one-page outline of the applicant's interest in developing their mental health skills and reason/s for seeking the scholarship, curriculum vitae and employer letter of support. Applicants did not need to currently work in the sector. All applications were reviewed by an independent panel involving representatives from the University, the sector, consumers and carers. University ethics approval was obtained (HSV/11/13/HREC).

\section{Participants and data collection}

Demographic information was obtained from initial scholarship applications from both cohorts (2013 and 2014), e.g. previous education and workplace location, as well as employer support letters and the student's motivations for tertiary education. Surveys and semi-structured 
interviews were undertaken with successful scholarship recipients; interviews also took place with the University course convenors and student employers. Informed consent was obtained from all individual participants included in this study (Figure 1).

\section{Questionnaires}

Three online questionnaires were sent to scholarship students: at study commencement (T1-q; May 2013 and March 2014); at the end of 12 months of study (T2-q; April 2014 and January 2015); and after 24 months of study or study completion (T3-q; January 2015). The questionnaires were developed as recommended by Neuman (2014, pp. 191-217), and included multiple choice, 7-point Likert scales and open-ended questions, which allowed students to describe their study experiences and goals. Questionnaires were piloted by two academics and a sector employee; minor changes were made to the wording. Students were invited to participate in each survey, which were administered online via LimeSurvey ${ }^{\odot}$. Reminder emails were sent to all participants for the first two time-points. T1-q included an invitation to participate in a semi-structured interview.

\section{Semi-structured interviews}

Interviews with scholarship applicants occurred after each questionnaire time-point (Figure 1). The interview guides were developed based on a literature review and discussion with other researchers. The guide was reviewed after the first interview at each time-point to ensure information gained was consistent with the research objectives. Questions explored the scholarship recipients' motivations for study, their study experience, strategies they put in place to manage their studies, the reasons they were attracted to the mental health field, their career path to date and future career intentions. Interviews were also sought with any student who withdrew from study to explore their reasons and study experiences. All interviews were conducted over the phone by the primary author and transcribed verbatim; all transcripts were quality checked.

Student consent was obtained prior to interviewing employers. Questions were designed to examine the organization's intentions behind supporting their employees to undertake higher education, their perceptions of the students' progress, as well as any perceived organizational benefits. The course convenors were crucial to the implementation of the scholarship program and worked closely with all scholarship recipients. Interviews with course convenors provided insight into the challenges faced by students, and the associated strategies to address these, as well as informing of possible program amendments to enhance the student experience.

\section{Data analysis}

The qualitative questionnaire responses and interview transcripts were coded and thematically analyzed using QSR NVivo $10^{\odot}$. The raw data went through first-pass open coding until a range of relevant themes and initial codes were identified; this was reviewed by another researcher. A second read through the data resulted in the development of axial codes based on emerging themes from the data and continued literature review. Axial coding occurred when the data started to cluster and key concepts began to emerge, and the researcher explored whether the codes were related, dependent or independent of each other (Neuman, 2006). The researchers continued to cross-check the coding and formalized higher-order themes.

Quantitative information (i.e. student applications and questionnaires) were imported into QSR NVivo $10^{\circ}$ which enabled comparative analysis and coding queries on student variables, e.g. gender, education level, employment position and study status (Bazeley and Jackson, 2013). Descriptive analysis of the scholarship applications, questionnaires and interview transcripts was undertaken for both cohorts (2013 and 2014).

\section{Results}

\section{Response rates and study progress}

In total, 19 students received a scholarship ( $n=15$ cohort 2013; $n=4$ cohort 2014) (Table I and Figure 2). Interviews were undertaken with two employers of two 2013 Master students and both course convenors. 
Table I Scholarship recipient's demographics over the research timeframe

$\begin{array}{cccc}\begin{array}{c}\text { Scholarship application } \\ (n=19)\end{array} & \text { T1 } & \text { T2 } & \text { T3 } \\ (n=17) & (n=11) & (n=8)\end{array}$

\begin{tabular}{|c|c|c|c|c|}
\hline $\begin{array}{l}\text { Degree enrolled } \\
\text { Master of MH Practice } \\
\text { Graduate Certificate }\end{array}$ & $\begin{array}{c}5 \\
14\end{array}$ & $\begin{array}{c}4 \\
13\end{array}$ & $\begin{array}{l}3 \\
8\end{array}$ & $\begin{array}{l}3 \\
5\end{array}$ \\
\hline \multicolumn{5}{|l|}{ Gender } \\
\hline Male & 4 & 4 & 2 & 1 \\
\hline Female & 15 & 13 & 9 & 7 \\
\hline \multicolumn{5}{|l|}{ Age range (years) } \\
\hline$\leqslant 35$ & 6 & 5 & 3 & 3 \\
\hline $36-55$ & 12 & 11 & 7 & 4 \\
\hline$>56$ & 1 & 1 & 1 & 1 \\
\hline \multicolumn{5}{|l|}{ Relationship status } \\
\hline Married & a & 8 & a & a \\
\hline In a relationship & & 4 & & \\
\hline Divorced/separated & & 1 & & \\
\hline Single & & 3 & & \\
\hline Unknown & & 1 & & \\
\hline \multicolumn{5}{|l|}{ Dependents ${ }^{b}$} \\
\hline Children & a & 9 & a & a \\
\hline Aging parents & & 5 & & \\
\hline Carer of person with a disability & & 9 & & \\
\hline \multicolumn{5}{|l|}{ Highest previous qualification ${ }^{c}$} \\
\hline Postgraduate degree & 1 & 1 & 1 & Nil \\
\hline Bachelor degree & 11 & 9 & 7 & 7 \\
\hline Vocational diploma & 7 & 7 & 3 & 1 \\
\hline \multicolumn{5}{|l|}{ Lived experience of mental illness } \\
\hline Yes & a & 9 & a & a \\
\hline No & & 8 & & \\
\hline \multicolumn{5}{|c|}{ Occupational sector } \\
\hline \multicolumn{5}{|l|}{ Community-managed mental health } \\
\hline Not working in sector & $\begin{array}{c}14 \\
5\end{array}$ & $\begin{array}{l}12 \\
5\end{array}$ & $\begin{array}{l}8 \\
3\end{array}$ & $\begin{array}{l}7 \\
1\end{array}$ \\
\hline \multicolumn{5}{|c|}{ Length of time in current employment } \\
\hline$<12$ months & 3 & 2 & 1 & 3 \\
\hline $1-2$ years & 2 & 2 & 2 & 2 \\
\hline 3-4 years & 10 & 10 & 7 & 2 \\
\hline $5-10$ years & 4 & 3 & Nil & Nil \\
\hline Unknown & Nil & Nil & 1 & 1 \\
\hline \multicolumn{5}{|l|}{ Employment status } \\
\hline Full-time & a & 15 & 8 & 5 \\
\hline Part-time & & 1 & 2 & 2 \\
\hline Unknown & & 1 & 1 & 1 \\
\hline \multicolumn{5}{|l|}{ Employment position } \\
\hline Support worker & 12 & 11 & 9 & 6 \\
\hline Manager & 6 & 5 & 1 & 1 \\
\hline Nurse & 1 & 1 & 1 & 1 \\
\hline \multicolumn{5}{|l|}{ Location } \\
\hline Brisbane & 14 & 12 & 9 & 7 \\
\hline Regional Queensland & 5 & 5 & 2 & 1 \\
\hline
\end{tabular}

Notes: ${ }^{a}$ Data were not collected at this time point; ${ }^{b}$ dependent total does not add to total number of participants. Some students had multiple dependents. Data sourced from the students' scholarship applications, course convenors and T1, T2 and T3 questionnaires and interviews; 'previous tertiary qualifications include management, nursing, social science, social work and psychology 


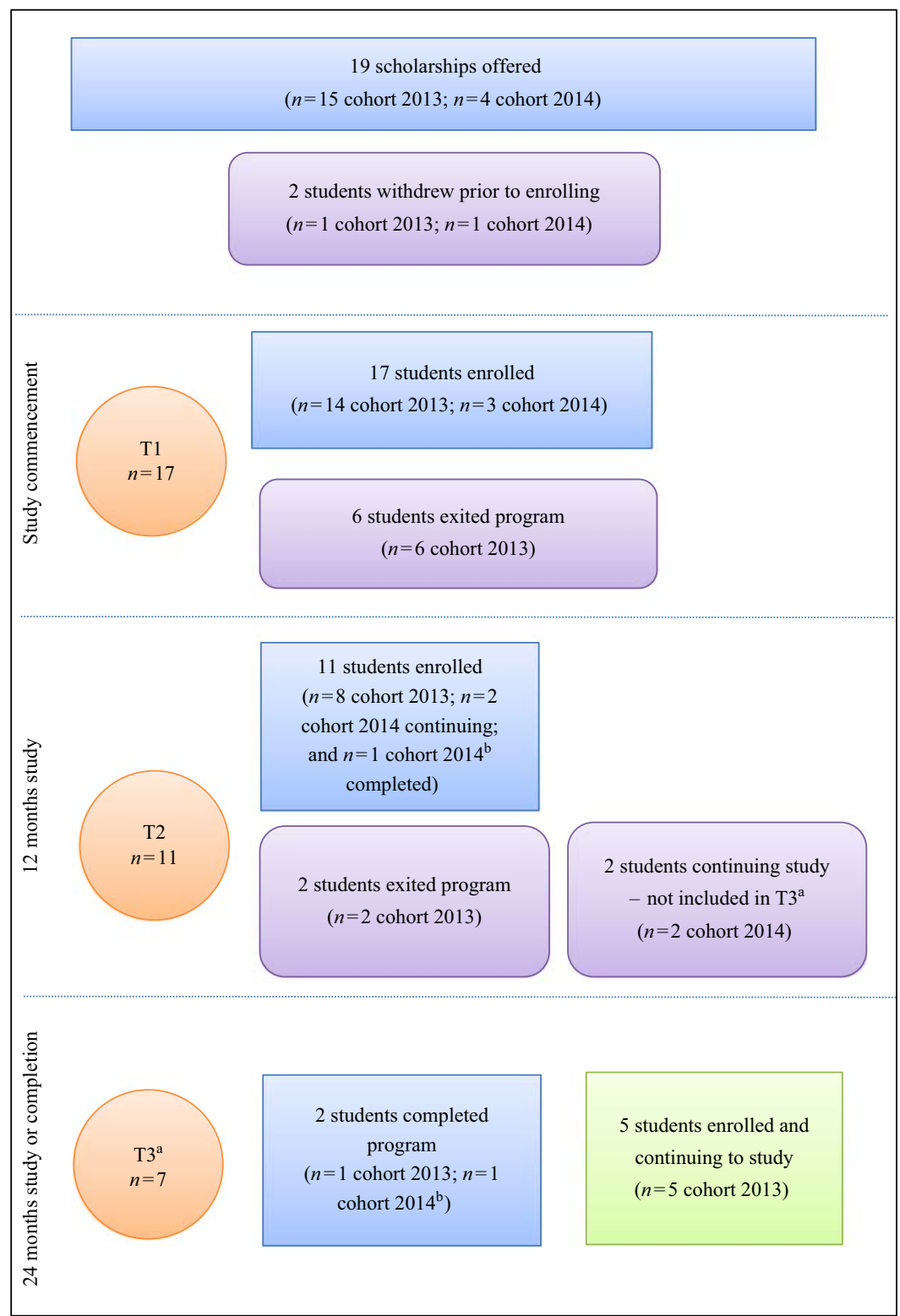

Notes: ${ }^{\mathrm{a} C o h o r t} 2013 \mathrm{~s}$ progress was followed over T1, T2 and T3. Cohort 2014s progress was followed over T1 and T2 only, with the exception of one student; ${ }^{b}$ who completed their qualification within 12 months. This student's data is captured at T1 and T3 only

Study entry (Baseline T1). Of the 19 scholarship recipients, 17 commenced study and completed T1-q $(n=14$ cohort 2013; $n=3$ cohort 2014). T1-i were conducted with seven commencing students ( $n=4$ cohort 2013; $n=3$ cohort 2014) and one student who exited before enrollment. At study entry, 70 percent $(n=12)$ of students were enrolled part-time and 88 percent $(n=15)$ worked full-time (Table I). Other commitments included caring for children (between 3 weeks to 26 years of age), older parents, and for another person with a disability and/or mental illness. Just over half of students (53 percent; $n=9$ ) identified as having a lived experience of mental illness and 12 (70 percent) worked in the community-managed mental health sector. When asked about their anticipated studying time, seven of 12 students 
expected to study beyond ten hours each week (a recommendation for each program course); others reported three to five hours per week.

Completion of 12 months study (T2). Seven responses (63 percent) were received for T2-q and six interviews (T2-i) were undertaken (Figure 2). One exit interview was completed with a Graduate Certificate (cohort 2013) student. A total of 11 students remained enrolled (Figure 2). In the first year of study five students had deferred at least one course: three had changed jobs, one student was on maternity leave, and one student was seeking employment after being made redundant. One cohort 2014 student (with a previous vocational qualification) had completed the Graduate Certificate in Mental Health Practice.

Program completion or two years study (T3). After two years five students (cohort 2013) remained enrolled, with another two having withdrawn (Figure 2). One Master student from cohort 2013 had already graduated and another enrolled Master student had completed and was due to graduate in early 2016. Two students responded to T3-q. Four interviews were conducted; three cohort 2013 Master students and one 2014 completing Graduate Certificate student. Two of the four interviews were with the female students who completed their qualifications; both were in relationships with no children and worked within the community-managed mental health sector. The Graduate Certificate student worked full-time and studied between six and ten hours per week. The Master student cared for a family member and studied part-time, spending more than ten hours studying per week.

\section{Themes}

Four higher-order themes are presented: motivations and benefits of study, challenges and managing study, career intentions and continuation/completion vs withdrawal.

Motivations and benefits of study. At baseline, the most commonly cited reason for study reported by students was to deepen their mental health knowledge and understanding, which would further assist consumers:

Workers who come into the field with a strong academic base and team it with compassion and practical skills are able to provide holistic, evidence-based practice that serves the client's best interests (Student 016, T1-q).

Students were motivated by the potential to improve their work practice, the opportunity to formalize their experience with a postgraduate qualification and future career progression. When asked what motivated them to continue with their study at T2-i, students referred to applying new knowledge in the workplace, and ultimately, having better career prospects. Some students discussed their enjoyment in developing their analytical skills and improving their ability to make connections between their learning, work practice and broader systemic concepts. This sentiment was supported by the two employers, who valued the professional development of their staff and provided support for them to study, e.g. provision of study leave:

We do regularly talk about where they are at and what they are doing in [student's name]'s course. They'll often make reference to things that they are learning. In terms of supporting them to get that done, they often had a day off and we've made that possible for them to be able to get assignments and get things done (Employer, 025).

While there was a balance to supporting and offering these development opportunities to staff in terms of cost and time, ultimately, the scholarship program was viewed as beneficial to their staff.

Students also commented on the benefits of a deeper understanding of mental health, which enabled them to engage more fully with other professionals:

[lt's] not about money so much or getting ahead in a financial way, although that is always nice, but it's not about that. What it comes down to is more challenging work. And it's opened up pathways as well, indirectly, if you're looking at relationships that you can form with staff (Student 001, T2-i).

One student indicated that studying had given them the opportunity to reflect on their career and the confidence to apply for a new position. 
Challenges and managing study. All students at baseline (T1) indicated a major concern was with time management, i.e. balancing home, work and study. Other challenges included maintaining concentration and energy, the online study environment, looking after themselves, meeting the associated financial costs of studying and the high academic expectations of the university. T1-i respondents referred to funding uncertainty within their employment organization as a major source of instability and stress, leading to difficulty in focusing on their studies. Two scholarship recipients (T1-i) lost their employment positions due to a reduction in service provider funding.

T2 interviewees were positive about the year, but confirmed that they had experienced several challenges during this period. Consistent with $\mathrm{T} 1$ responses, managing time and resources, work/life balance and an initial lack of understanding regarding the expectations and standard of work required for postgraduate study, were key challenges. Some students reported pressure from work colleagues to follow a more clinical or professional career study pathway.

Time-management strategies were used to overcome these challenges. Students needed to be well organized, and learnt to be flexible with work, study and personal commitments. Other strategies included: undertaking a pre-study course on online learning; finding a "study buddy"; reading assignment requirements early in the semester; and setting a particular GPA outcome as a goal. Most students reported that they had become more comfortable with the online learning platform and enjoyed the flexibility it granted them around work and social commitments, as well as the ability to connect with other students for support:

I actually really like it [online study]. I reached out to one particular student who was really struggling and I felt like if I was in the same position, I'd really want someone to go 'hey mate, I'm doing the same topic as you and we can have a chat through it'. I did feel a sense of community [...] (Student 020, T2-i).

Unforeseen and unplanned events posed a major challenge to students, such as pregnancy $(n=4)$, health issues $(n=3)$, redundancy $(n=3)$ and other family issues $(n=3)$, e.g. death, terminal illness or a combination of these. One student found the online environment very challenging, and despite support from the University, did not continue. Overall, 10 of the 19 scholarship recipients were not enrolled by the 24 month time-point (T3). T3-q respondents explained that maintaining a work/life balance, and the ongoing motivation to continue studying, required particular effort. Again, unforeseen events, such as a suicide at work and the death of a parent took priority, but these students were able to re-focus and complete their studies.

These challenges were reinforced by course convenors, who felt that students needed to fully understand the commitment and volume of work required for university study. It was acknowledged that the scholarships assisted sector workers to enhance their academic and research abilities, yet students with previous university experience appeared to complete their studies more easily than their peers with vocational qualifications:

[...] the students who come in without an undergraduate degree struggle with the academic writing.

Struggle with understanding how university works and the expectation (Course Convenor, 023).

In contrast to the course convenors' experience, the first student to fully finish the Graduate Certificate, within the minimum timeframe, had no previous university qualification.

Career intentions. At T1, students had difficulty knowing what they would do career wise after completing their study. T2-q respondents were asked how long they intended to stay in their current employment. The four students who were working in the community-managed mental health sector at this time indicated between two and four years $(n=2)$, or up to or greater than five years $(n=2)$. This showed an ongoing commitment to the sector, with the primary factor expressed being the desire to help others:

I have a passion to help people who are marginalized due to a diagnosis of mental illness. The community sector allows me more flexibility to advocate for people and make a difference in individual lives (Student 001, T2-i).

The three students not working in the community-managed mental health sector were asked why this was the case, and what would attract them to, or discourage them from, this sector. Personal mental health issues, redundancy, or working in an alternate mental health area, e.g. in the 
homeless sector, were cited. Factors that would make the sector more attractive included the availability of sector positions and greater remuneration:

[...] my five years' experience is valued as a min[imum] under $\$ 20$ per hour pay rate. Shoots my study and hard work down in flames (Student 018, T2-q).

Both course convenors acknowledged that there were limited career options for community-managed mental health workers, and were keen to see formal acknowledgment of this workforce and further developmental opportunities for staff:

The sector itself is evolving in terms of its identity, professionalism, ability to take different skills, knowledge, conceptual paradigms. I don't think you can continue to expect people to develop their skills and qualifications and not reward and recognize that (Course Convenor 022).

T3-i respondents indicated a desire to remain working in the sector because of the consumers they supported and their belief that mental illness can affect anyone. In terms of their next career move, participants indicated further study or professional development, as well as seeking more senior or management level roles.

Continuation/completion vs withdrawal. Scholarship students showed diverse outcomes in their study journey; two students (one from each cohort) completed their studies, and eight cohort 2013 students ( $n=6$ first year; $n=2$ second year) withdrew after study commencement. Course convenors confirmed that the drop-out and continuing rates were similar between the scholarship and non-scholarship students within the same program. The majority of students ( $n=7 ; 87$ percent) confirmed that unforeseen personal circumstances were the main reasons for drop-out:

So I received a redundancy and got put out to pasture. I didn't have enough mental capacity to focus on studying and looking for a job and also caring for my family and lots of responsibilities (Student 003, T1-i).

Despite experiencing a number of events that had the potential to disrupt their study goals, a number of factors were identified that facilitated study continuation (Table II). The course convenors indicated that students who were curious, passionate about learning and willing to ask questions appeared to manage their study more easily:

The people, who were willing to ring, ask questions, willing to email and ask lots of questions, probably did better than the ones who didn't. I think you do have to be a very resilient person and to take some blows (Course Convenor 022).

For six students, reaching the end of the second year of study was a significant achievement. These students found studying relevant to their work, enjoyed translating their new knowledge into practice, and were stimulated to reflect on their practice and continue professional development. Making time and managing their motivation continued to be key study challenges, whereas support from family, friends or colleagues, resilience, a strong internal drive and a clear perception of study benefits, were facilitators for ongoing study:

So talk about massive saturation. It's been a slog. It has come with its challenges, but it hasn't been anything that I couldn't overcome. That's what I guess is exciting about it and I think I'm just addicted to study [...] (Student 001, T3-i).

\section{Discussion}

This research identified that mental health scholarship recipients were a cohort, for whom professional development was important, but required tertiary education to be

\section{Table II Factors influencing a student's ability to continue study}

Support from family, other student or work Ability to manage and motivate oneself Ability to manage time, resources and immediate environment

Resilience
Realizing improved work practice as a result of study Maintaining flexibility

Commitment to sector and consumer outcomes Ability to identify and maintain focus on goals and motivations for study 
delivered in a way that suited their life circumstances. External factors impacting on a student's study journey included the student's health, work and family commitments, available study time, access to support and financial assistance. Significant changes or disruptions to these factors were challenges that students needed to overcome to continue studying. Internal factors included a student's motivation for study, organizational skills, ability to apply new knowledge, personal resilience, flexibility and a strong work commitment within the sector. Lastly, scholarship recipients maintained high levels of motivation to remain connected to the sector, regardless of whether they had completed their academic qualification.

In a study on the unique factors associated with persistence in online tertiary programs, Hart (2012) identified that social connectedness, motivation, time management skills, communication with course convenors, and support promote student persistence. These factors are not related to the person's intelligence or knowledge, but enable "the student to overcome hardships in completing a course" (Hart, 2012). Similar to other Australian research, scholarship recipients appeared to benefit when they received support for their studies via their employer, family and friends, or other students (Holden, 2005; Black and Bonner, 2011; Gibbons and Shannon, 2013).

The importance of a supportive environment was underscored by the two students who completed their qualifications. Accessing structured supports, particularly through employers, is recommended by Black and Bonner (2011), who surveyed the support provided to nurse employees undergoing distance education. Ultimately, employers can implement various support mechanisms for employees who are studying, including study leave, access to resources and study buddies (Andrews and Harris, 2009; Buykx et al., 2010; Black and Bonner, 2011; Cleary et al., 2013; Gibbons and Shannon, 2013). Access to study leave was the main employer support provided to scholarship recipients, although the two interviewed employers explained that time was also made for students to discuss their study with their manager and reflect on how their learning influenced their work practice.

There were wide-ranging benefits of postgraduate study for scholarship students. These benefits can be articulated to future sector workers as encouragement to undertake further study and continued professional development, which could enhance their decision to remain in the sector. Upon study commencement, scholarship recipients hoped to strengthen their mental health knowledge, widen their scope of practice, gain recognition of their skills and abilities, and improve service delivery and their career prospects. These desires are consistent with literature focusing on tertiary students undertaking professional development activities to build on their work-related experience (Andrews and Harris, 2009; $\mathrm{Ng}$ and Feldman, 2009; Gibbons and Shannon, 2013) and were confirmed as benefits by the students at T2 and T3. Students emphasized the pleasure they experienced when applying their knowledge at work, engaging in stimulating discussions with other colleagues and seeing enhanced outcomes for mental health consumers. Indeed, postgraduate study could prompt students to make more sense of their environment and facilitate strategic planning, which could have a significant impact on workplace retention (Andrews and Harris, 2009). The practical application of newfound knowledge in their job motivated students to continue studying.

Increased job satisfaction (Robertson et al., 1999; Rambur et al., 2005; Wilson, 2005; Fabra and Camisón, 2009) and access to research relevant to their field of practice (Jeffers et al., 2008) are reported benefits of academic study. Although these were not specifically mentioned by our participants, students reported improved self-confidence and a broader strategic understanding of their work. Two students acknowledged that study had increased their confidence to apply for new sector positions, demonstrating that tertiary study improves self-esteem (Gibbons and Shannon, 2013). Maintaining currency and being exposed to advanced mental health practice may be an underlying benefit for the scholarship recipients, who reported improved work practice as a result of their academic study.

Scholarship students identified a number of potential challenges at study commencement, many of which remained constant as their studies progressed. These challenges are consistent

\begin{tabular}{l|l|l} 
PAGE 370 & THE JOURNAL OF MENTAL HEALTH TRAINING, EDUCATION AND PRACTICE & VOL. 12 NO. 62017
\end{tabular} 
with other postgraduate literature (Andrews and Harris, 2009; O'Donnell et al., 2009; Gibbons and Shannon, 2013; Shandler and Steenekamp, 2014). Oman et al. (2012) concluded that students struggle "to cope with the demands" of their study alongside work, family and financial commitments. O'Donnell et al. (2009) suggested that this is largely because the majority of postgraduate students are adults who have returned to study after several years in the workforce. The greatest challenge for the scholarship students was the unexpected events and circumstances that could not be predicted nor planned for, such as personal or family member health issues, job insecurity or complex workloads. Furthermore, scholarship students were required to juggle their commitments and themselves in light of changing circumstances within the sector (Australian Council of Social Services, 2013). For many this led to withdrawing from study as the challenges became unmanageable; however, this was not significantly dissimilar to the overall program rates discussed with the course convenors. The rate of withdrawal also appears consistent with other scholarship evaluation studies (Pathman et al., 2004; Wilson, 2005; Duffourc, 2006; Hungerford and Hodgson, 2013), as do the reasons for withdrawal being more related to personal circumstances than any particular problem with the program of study or the scholarship initiative (Hungerford and Hodgson, 2013).

One challenge that appeared to diminish over the research timeframe was the scholarship participants' concern that they could not use or adapt to studying via an online platform. Lewis (2009) explains that the "paradigm shift" from face-to-face to online learning can be challenging, but if the learner is committed they can master this mode; a sentiment echoed by others (Kahu et al., 2014; Posey and Pintz, 2014; Oman et al., 2012). Universities are encouraged to support a student's transition to online learning by providing access to orientation modules prior to study commencement, creating relationships with course convenors, peer mentors and other students, and responding to the diverse needs of students (Moore and Fetzner, 2010; Milman, 2013; Posey and Pintz, 2014). The University provides many of these support strategies with the intent to facilitate student success with online programs. Active encouragement to participate in these programs was offered by the course convenors; however the number of scholarship recipients who enrolled is not known. This information would be useful to track future students and their study progress following completion of such orientation programs.

There is an emerging international trend towards workers requiring higher education qualifications to meet the need for a more skilled and adaptable workforce; mature-age, parttime students with considerable work experience form a large part of this workforce (Gibbons and Shannon 2013; O'Donnell et al., 2009). Many scholarship initiatives have been aimed at new graduates or entrance-level workers, but few initiatives target the older worker or are aimed at developing and maintaining the experience of these workers (Foreman et al., 2015). A variety of supports need to be implemented, acknowledging the diverse demands, needs and personal commitments of older students (O'Donnell et al., 2009; Black and Bonner, 2011; Jeffers et al., 2008). This was a critical element reinforced during the scholarship study and must be considered when designing future initiatives.

Notably, this study did not find any difference in the benefits and challenges experienced by scholarship recipients enrolled in the Master or Graduate Certificate qualification. It also appeared that there was little difference between the programs with regard to the students' internal capabilities and external factors that enabled them to manage their study. In the case of the two completing students (one from each qualification), it was identified that the main characteristic that set these students apart from others was their ability to organize themselves, build their support networks and their determination to finish; failure was not an option. Internal skills and attributes assisted both students to manage their studies; further research is needed to examine the predictive possibilities of various external and intrinsic factors that enable a student to complete postgraduate study. Future research could include a comparison group with non-scholarship mental health practice students to explore the challenges and benefits experienced more broadly, and whether the academic experience differs between the two groups. Examination of scholarship initiatives within other similar workforces could also be undertaken. 
In terms of career intentions, all study participants indicated a desire to continue working in the mental health sector whilst they were studying and into the future. Notably, many students specified their preference for the community-managed mental health sector. The timeframe of this research did not allow the opportunity to follow students after graduation, however, the literature indicates that work-related study may be a determinant of career retention and can support career advancement (Buchan, 2002; Rambur et al., 2005; Wilson, 2005; Aarons and Sawitzky, 2006; Andrews and Harris, 2009; Scanlan et al., 2010; Maxwell-Crawford, 2011). The most compelling research would be to continue to follow the scholarship students longitudinally to explore whether the completion of higher education maintains their motivation and intention to remain in the sector (Andrews and Harris, 2009; Yin, 2014).

Research examining the impact of education on job performance found that an individual's education level is positively associated with career progress and attainment of higher remuneration and opportunities ( $\mathrm{Ng}$ and Feldman, 2009). Employers may benefit from exploring opportunities to support their staff to advance their education, but this should not be done in isolation. A broader workforce strategy that acknowledges the impact of the team environment, management styles, work entitlements and remuneration, career pathways and other influencing factors that determine an individual's willingness to stay in their chosen field of employment, is required (Huang et al., 2004; Happell, 2008; Buykx et al., 2010; Keane et al., 2011; Cleary et al., 2013).

\section{Strengths and limitations}

The scholarship initiative was the first of its kind for the Queensland community-managed mental health sector, and the evaluation of this initiative contributes significant knowledge to the limited scholarship literature. The sample size was small but aligns with the exploratory nature of this study. The research was limited by the withdrawal of students from the program; exit interviews with these students were extremely difficult to procure and would have provided valuable information. The withdrawal of students further resulted in limited access to employers; future workforce research for the community-managed mental health sector would benefit from further insights from this group. The research is also subject to participant self-reported bias.

This scholarship program was introduced just prior to a time of significant change to government funding in Queensland, which was not able to be predicted prior to the research commencement and is part the nature of "real-world" research. The impact of this reform is considered a limitation; however, the researchers found that despite job insecurity and workload issues, participants maintained a strong desire to remain working in the sector. Furthermore, participants stated that study (even if not completed) was a contributing factor in reinforcing this commitment. Notably, no students withdrew from the second cohort who were offered scholarships after the funding reform had occurred.

Education is only one element impacting on retention within the workforce and so an additional limitation is the singular focus on the scholarship initiative as a means to maintain and develop the community-managed mental health sector. However, due to the limited research on scholarship initiatives this work is important. While the study was based on a scholarship program in one university, the findings have applicability to other workforces. There is now a need to extend the research to other sectors, to test these recommendations.

\section{Conclusion}

The provision of higher education as a workforce strategy for the community-managed mental health sector requires tailoring to meet the unique needs of this workforce. The benefits realized and the challenges faced by the scholarship recipients informs ongoing workforce development programs for the community-managed mental health sector and has relevance to other sectors seeking to develop and maintain their workforce. Scholarship students were keen to continue working in the mental health sector; whether this occurs, and justifies the investment in scholarships as a workforce strategy, requires further investigation. 


\section{References}

Aarons, G. and Sawitzky, A. (2006), "Organizational climate partially mediates the effect of culture on work attitudes and staff turnover in Mental Health Services", Administration and Policy in Mental Health and Mental Health Services Research, Vol. 33 No. 3, pp. 289-301.

Akingbola, K. (2004), "Staffing, retention, and government funding: a case study", Nonprofit Management \& Leadership, Vol. 14 No. 4, pp. 453-65.

Andrews, G. (2005), "The crisis in mental health: the chariot needs one horseman", Medical Journal of Australia, Vol. 182 No. 8, pp. 372-3.

Andrews, J. and Harris, M. (2009), "Postgraduate study and managers' subsequent work experience: an exploratory evaluation", Assessment \& Evaluation in Higher Education, Vol. 34 No. 4, pp. 427-38.

Australian Council of Social Services (2013), "Australian community sector survey 2013 national report", ACOSS, Strawberry Hills.

Baran, M. and Jones, J. (2016), Mixed Methods Research for Improved Scientific Study, Ringgold Inc., Beaverton, OR.

Bateman, J. and Smith, T. (2011), "Taking our place. Community managed mental health services in Australia", International Journal of Mental Health, Vol. 40 No. 2, pp. 55-71.

Bazeley, P. and Jackson, K. (2013), Qualitative Data Analysis with NVIVO, SAGE Publications Ltd, London.

Black, K.E. and Bonner, A. (2011), "Employer-based support for registered nurses undertaking postgraduate study via distance education", Nurse Education Today, Vol. 31 No. 2, pp. 163-7.

Brough, P., Holt, J., Bauld, R., Biggs, A. and Ryan, C. (2008), "The ability of work - life balance policies to influence key social/organisational issues”, Asia Pacific Journal of Human Resources, Vol. 46 No. 3, pp. 261-74.

Buchan, J. (2002), "Global nursing shortages: are often a symptom of wider health system or societal ailments", BMJ, Vol. 324 No. 7340, pp. 751-2.

Buykx, P., Humphreys, J., Wakerman, J. and Pashen, D. (2010), "Systematic review of effective retention incentives for health workers in rural and remote areas: towards evidence-based policy", The Australian Journal of Rural Health, Vol. 18 No. 3, pp. 102-09.

Canadian Mental Health Association (2012), "Strengthening our collective impact: a strategic plan for CMHA 2012-2017”, Canadian Mental Health Association.

Carbone, S., Rickwood, D. and Tanti, C. (2011), "Workforce shortages and their impact on Australian youth mental health service reform", Advances in Mental Health, Vol. 10 No. 1, pp. 92-7.

Cleary, M., Horsfall, J., Muthulakshmi, P., Happell, B. and Hunt, G. (2013), "Career development: graduate nurse views", Journal of Clinical Nursing, Vol. 22 Nos 17-18, pp. 2605-13.

Community Mental Health Australia (2012), "Taking our place: working together to improve mental health in the community", Community Mental Health Australia, Sydney.

Community Services and Health Industry Skills Council (2012), "2012 Community Services and Health Industry Skills Council Environmental Scan", Community Services and Health Industry Skills Council, Strawberry Hills.

Community Services and Health Industry Skills Council (2015), "2015 Environmental scan. Building a healthy future: skills, planning and enterprise", available at: www.cshisc.com.au/media/373197/EScan_2015_FULL_ VERSION.pdf (accessed October 23, 2016).

Creswell, J. and Plano Clark, V. (2011), Designing and Conducting Mixed Methods Research, SAGE Publications, CA.

Cuthbert, S. and Basset, T. (2007), "The non-professionally affiliated workforce in mental health - who are these generic mental health workers and where do they fit within a workforce strategy?", The Journal of Mental Health Training, Education, and Practice, Vol. 2 No. 3, pp. 4-11.

Davidson, E. (2005), Evaluation Methodology Basics: The Nuts and Bolts of Sound Evaluation, SAGE Publications, Inc., Thousand Oaks, CA.

Department of Health and Ageing (2013), "National mental health report 2013", Tracking progress of mental health reform in Australia, 1993-2011, Commonwealth of Australia, Canberra. 
Doessel, D., Tonmukayakul, U. and Williams, R. (2011), "Quantifying the economic structure of the Australian mental health sector since 1992-93", International Journal of Mental Health, Vol. 40 No. 2, pp. 25-54.

Duffourc, D. (2006), "State-funded college scholarships: general definitions and characteristics", Review of Policy Research, Vol. 23 No. 1, pp. 235-48.

Fabra, M.E. and Camisón, C. (2009), "Direct and indirect effects of education on job satisfaction: a structural equation model for the Spanish case", Economics of Education Review, Vol. 28 No. 5, pp. 600-10.

Foreman, E., Perry, C. and Wheeler, A. (2015), "Higher education scholarships: a review of their impact on workplace retention and career progression", Open Review of Educational Research, Vol. 2 No. 1, pp. 155-66.

Gallon, S., Gabriel, R. and Knudsen, J. (2003), "The toughest job you'll ever love: a pacific Northwest treatment workforce survey", Journal of Substance Abuse Treatment, Vol. 24 No. 3, pp. 183-96.

Gethin, A. and Deakin, E. (2006), "Mental health training needs assessment for the NGO sector in NSW", Mental Health Coordinating Council.

Gibbons, A. and Shannon, E. (2013), "Tertiary study: barriers and benefits for health and human services professionals", Australian Journal of Adult Learning, Vol. 53 No. 3, pp. 436-56.

Greene, J.C., Caracelli, V.J. and Graham, W.F. (1989), "Toward a conceptual framework for mixed-method evaluation designs", Educational Evaluation and Policy Analysis, Vol. 11 No. 3, pp. 255-74.

Griffith University (2012), "New mental health scholarships at Griffith”, available at: https://app.secure.griffith. edu.au/news/2012/12/10/new-mental-health-scholarships-at-griffith/ (accessed January 22, 2015).

Griffith University (2014), "Mental health practice", available at: www.griffith.edu.au/health/mental-health/ what-can-i-study/mental-health-practice (accessed January 15, 2014).

Happell, B. (2008), "Putting all the pieces together: exploring workforce issues in mental health nursing", Contemporary Nurse, Vol. 29 No. 1, pp. 43-52.

Harkness, E., Bower, P., Gask, L. and Sibbald, B. (2007), "Retention and future job intentions of graduate primary care mental health workers: a newly developed role in England", Journal of Health Services Research \& Policy, Vol. 12 No. S1, pp. 18-22.

Hart, C. (2012), "Factors associated with student persistence in an online program of study: a review of the literature", Journal of Interactive Online Learning, Vol. 11 No. 1, pp. 19-42.

Health and Community Services Workforce Council (2012), "Final report: community mental health skills formation strategy", Health and Community Services Workforce Council, Brisbane.

Health Workforce Australia (2011), "National health workforce innovation and reform strategic framework for action 2011-2015", Health Workforce Australia, Adelaide.

Holden, H. (2005), "A Qualitative study of persistence and performance: factors in the motivation of first year tertiary education students", Education in Rural Australia, Vol. 15 No. 1, pp. 28-40.

Huang, L., Macbeth, G., Dodge, J. and Jacobstein, D. (2004), "Transforming the workforce in children's mental health", Administration and Policy in Mental Health and Mental Health Services Research, Vol. 32 No. 2, pp. 167-87.

Hungerford, C. and Hodgson, D. (2013), "Addressing mental health nursing workforce issues in Australia: a case study analysis", The Journal of Mental Health Training, Education, and Practice, Vol. 8 No. 2, pp. 89-102.

James, A., Chadwick, S. and Rushforth, D. (2006), "Implementing a new national role in mental health: the support, time and recovery worker", The Journal of Mental Health Workforce Development, Vol. 1 No. 1 , pp. 30-36.

Jeffers, L., Moseley, A. and Paterson, J. (2008), "The retention of the older nursing workforce: a literature review exploring factors that influence the retention and turnover of older nurses", Contemporary Nurse, Vol. 30 No. 1, pp. 46-54.

Kahu, E., Stephens, C., Zepke, N. and Leach, L. (2014), "Space and time to engage: mature-aged distance students learn to fit study into their lives", International Journal of Lifelong Education, Vol. 33 No. 4, pp. 523-40.

Keane, S., Smith, T., Lincoln, M. and Fisher, K. (2011), "Survey of the rural allied health workforce in New South Wales to inform recruitment and retention", Australian Journal of Rural Health, Vol. 19 No. 1, pp. 38-44. 
Lewis, A. (2009), "E-learning and mature-aged learners", Training and Development in Australia, Vol. 36 No. 1, pp. 26-8.

Maxwell-Crawford, K. (2011), "Indigenous workforce development in Aotearoa", Pimatisiwin: A Journal of Aboriginal and Indigenous Community Health, Vol. 9 No. 1, pp. 53-64.

Mendoza, J. and Wands, M. (2009a), "Queensland NGO mental health sector training analysis - Final report", ConNetica Consulting, Brisbane.

Mendoza, J. and Wands, M. (2009b), "Queensland NGO mental health sector workforce analysis", ConNetica Consulting, Brisbane.

Mental Health Workforce Advisory Committee (MHWAC) (2011a), National Mental Health Workforce Plan, Department of Health and Ageing, Victoria.

Mental Health Workforce Advisory Committee (MHWAC) (2011b), National Mental Health Workforce Strategy, Department of Health and Ageing, Victoria.

Milman, N.B. (2013), "Increasing student success in online courses examining existing research and the need for even more!”, Distance Learning, Vol. 10 No. 3, pp. 63-5.

Moore, J. and Fetzner, M. (2010), "The road to retention: a closer look at institutions that achieve high course completion rates”, Journal of Asynchronous Learning Networks, Vol. 13 No. 3, pp. 3-22.

National Health Workforce Planning and Research Collaboration (NHWP\&Rc) (2011), "Mental Health NGO workforce project final report", Health Workforce Australia, Adelaide.

Neuman, L. (2014), Basics of Social Research: Qualitative and Quantitative Approaches, Pearson Education Limited.

Neuman, W. (2006), Social Research Methods - Qualitative and Quantitative Approaches, Pearson Education Inc., Boston, MA.

Ng, T. and Feldman, D. (2009), "How broadly does education contribute to job performance?", Personnel Psychology, Vol. 62 No. 1, pp. 89-134.

O'Donnell, V., Tobbell, J., Lawthom, R. and Zammit, M. (2009), "Transition to post-graduate study. Practice, participation and the widening participation agenda", Active Learning in Higher Education, Vol. 10 No. 1, pp. 26-40.

Oman, K., Rodgers, E., Usher, K. and Moulds, R. (2012), "Scaling up specialist training in developing countries: lessons learned from the first 12 years of regional postgraduate training in Fiji- a case study", Human Resources for Health, Vol. 10 No. 48, pp. 1-10.

Pathman, D., Konrad, T., King, T., Taylor, D. and Koch, G. (2004), "Outcomes of states' scholarship, loan repayment, and related programs for physicians”, Medical Care, Vol. 42 No. 6, pp. 560-8.

Platform (2007), NgOIT Workforce Survey, Ministry of Health.

Posey, L. and Pintz, C. (2014), "Easing students' transition to online graduate education", Distance Learning, Vol. 11 No. 1, pp. 63-66.

Queensland Government (2011a), "Queensland Plan for Mental Health 2007-2017 Four Year Report", Queensland Government, Brisbane.

Queensland Government (2011b), "Supporting recovery. Mental health community services plan 2011-2017", Department of Communities, Queensland Government, Brisbane.

Queensland Mental Health Commission (2014), "Improving mental health and wellbeing. Queensland mental health, drug and alcohol strategic plan 2014-2019”, Queensland Government, Brisbane.

Rambur, B., Mcintosh, B., Palumbo, M. and Reinier, K. (2005), "Education as a determinant of career retention and job satisfaction among registered nurses”, Journal of Nursing Scholarship, Vol. 37 No. 2, pp. 185-92.

Robertson, E., Higgins, L., Rozmus, C. and Robinson, J. (1999), "Association between continuing education and job satisfaction of nurses employed in long-term care facilities", The Journal of Continuing Education in Nursing, Vol. 30 No. 3, pp. 108-13.

Scanlan, J., Still, M., Stewart, K. and Croaker, J. (2010), "Recruitment and retention issues for occupational therapists in mental health: balancing the pull and the push", Australian Occupational Therapy Journal, Vol. 57 No. 2, pp. 102-10. 
Shandler, M. and Steenekamp, K. (2014), "Some prerequisities for access programmes that contribute to academic success in higher education", African Education Review, Vol. 11 No. 2, pp. 201-18.

Stewart, V., Fielden, J., Harris, M. and Wheeler, A. (2012), "Making mental health practitioners workforce ready", The Journal of Mental Health Training, Education, and Practice, Vol. 7 No. 3, pp. 124-32.

Wilson, A. (2005), "Impact of management development on nurse retention", Nursing Administration Quarterly, Vol. 29 No. 2, pp. 137-45.

World Health Organisation (2013), Mental Health Action Plan 2013-2020, World Health Organisation, Geneva. Yin, R. (2014), Case Study Research. Design and Methods, SAGE Publications Inc., CA.

\section{Further reading}

Department of Health (2009), "Shaping the future: the Victorian mental health workforce strategy", Final report, Department of Health, Melbourne.

\section{Corresponding author}

Sara McMillan can be contacted at: s.mcmillan@griffith.edu.au

For instructions on how to order reprints of this article, please visit our website: www.emeraldgrouppublishing.com/licensing/reprints.htm

Or contact us for further details: permissions@emeraldinsight.com 